\title{
Efficacy of capacitive resistive monopolar radiofrequency in the physiotherapeutic treatment of chronic pelvic pain syndrome: study protocol for a randomized controlled trial
}

\author{
A. Carralero-Martínez ${ }^{1,2}$, M. A. Muñoz Pérez ${ }^{3,4,5}$, R. Pané-Alemany' ${ }^{1}$ L. Blanco-Ratto ${ }^{1,6}$, S. Kauffmann ${ }^{1,6,7}$ and \\ I. Ramírez-García $a^{1,8,9,10^{*}}$ (1)
}

\begin{abstract}
Background: Chronic pelvic pain syndrome (CPPS) is a multifactorial disorder that affects $5.7 \%$ to $26.6 \%$ of women and $2.2 \%$ to $9.7 \%$ of men, characterized by hypersensitivity of the central and peripheral nervous system affecting bladder and genital function. People with CPPS have much higher rates of psychological disorders (anxiety, depression, and catastrophizing) that increase the severity of chronic pain and worsen quality of life. Myofascial therapy, manual therapy, and treatment of trigger points are proven therapeutic options for this syndrome. This study aims to evaluate the efficacy of capacitive resistive monopolar radiofrequency (CRMRF) at $448 \mathrm{kHz}$ as an adjunct treatment to other physiotherapeutic techniques for reducing pain and improving the quality of life of patients with CPPS.
\end{abstract}

Methods: This triple-blind (1:1) randomized controlled trial will include 80 women and men with CPPS. Participants will be randomized into a CRMRF activated group or a CRMRF deactivated group and receive physiotherapeutic techniques and pain education. The groups will undergo treatment for 10 consecutive weeks. At the beginning of the trial there will be an evaluation of pain intensity (using VAS), quality of life (using the SF-12), kinesiophobia (using the TSK-11), and catastrophism (using the PCS), as well as at the sixth and tenth sessions.

Discussion: The results of this study will show that CRMRF benefits the treatment of patients with CPPS, together with physiotherapeutic techniques and pain education. These results could offer an alternative conservative treatment option for these patients.

Trial registration: ClinicalTrials.gov NCT03797911. Registered on 8 January 2019.

Keywords: Chronic pelvic pain syndrome, Musculoskeletal pain, Physical therapy, Therapeutic interventions, Capacitive resistive monopolar radiofrequency, Randomized controlled trial, Gynecology, Urology

\footnotetext{
* Correspondence: inesrg@blanquerna.url.edu

'Rehabilitación Abdomino-Pelviana (RAPbarcelona SL), Barcelona, Spain

${ }^{8}$ Servicio de Fisioterapia, Instituto Médico Tecnológico SL, Barcelona, Spain

Full list of author information is available at the end of the article
}

(c) The Author(s). 2021 Open Access This article is licensed under a Creative Commons Attribution 4.0 International License, which permits use, sharing, adaptation, distribution and reproduction in any medium or format, as long as you give appropriate credit to the original author(s) and the source, provide a link to the Creative Commons licence, and indicate if changes were made. The images or other third party material in this article are included in the article's Creative Commons licence, unless indicated otherwise in a credit line to the material. If material is not included in the article's Creative Commons licence and your intended use is not permitted by statutory regulation or exceeds the permitted use, you will need to obtain permission directly from the copyright holder. To view a copy of this licence, visit http://creativecommons.org/licenses/by/4.0/. The Creative Commons Public Domain Dedication waiver (http://creativecommons.org/publicdomain/zero/1.0/) applies to the data made available in this article, unless otherwise stated in a credit line to the data. 


\section{Background}

Chronic pelvic pain syndrome (CPPS) is defined as "pain of non-oncological cause, intermittent or constant, in the lower part of the abdomen or pelvis, in both men and women, lasting at least 6 months, and with negative consequences that can be cognitive, behavioral, sexual and emotional" $[1,2]$. It is a multifactorial disorder serious enough to cause urinary and genital functional disability and with high prevalence rates $(5.7 \%$ to $26.6 \%$ of women and $2.2 \%$ to $9.7 \%$ of men) [3-8].

People with CPPS have much higher rates of psychological distress. The prevalence of anxiety ranges between 39 and $73 \%$, compared to $12 \%$ of the general population, while depression is seen in 26 to $52 \%$, compared to between 5 and $10 \%$ of the general population [9-13]. These conditions, along with catastrophizing, are associated with increased severity of chronic pain and reduced quality of life [4, 14-18].

In addition, people with CPPS tend to have central and peripheral nervous system hypersensitivity, with dysfunctional pain modulation that tends to aggravate pain [19-24].

In physical therapy consultations, there are a variety of therapeutic options with sufficient evidence to guide physical therapy for patients with CPPS [25]. The most widely used is myofascial therapy, although these patients should be treated using a multidisciplinary approach including other therapies such as psychology, medication, or surgery when other treatments have failed [26, 27]. One such option in clinical practice is capacitive resistive monopolar radiofrequency (CRMRF) at $448 \mathrm{kHz}$. This non-invasive strategy increases the temperature of deep organs or tissues using radiofrequency electrical currents to reduce pain and inflammation and increase tissue repair [28-35]. Few recent studies evaluate its clinical efficacy despite being common practice for the last 20 years [36]. Current studies report promising results in terms of pain reduction and improved function in musculoskeletal pathologies (such as low back pain) [37] and tendinopathies (such as plantar fasciitis) [38-40].

Despite its demonstrated efficacy in other musculoskeletal pathologies, there is currently insufficient scientific evidence regarding its role in the management of CPPS.

\section{Methods}

Aim

The superiority study hypothesizes that the application of CRMRF associated with physiotherapy techniques and health education provides benefits in reducing pain when compared to physiotherapy and health education techniques alone in patients with CPPS.
The specific aims are to evaluate the efficacy of the CRMRF according to the intensity of pain, quality of life, kinesiophobia, and catastrophism of patients participating in the study. In addition, sociodemographic and clinical data, adherence to treatment, and possible adverse events during treatment will be recorded for both groups.

\section{Design}

This manuscript describes a research protocol for a triple-blind, randomized controlled clinical trial. Participants will be equally (1:1) and randomly allocated into either an activated capacitive resistive monopolar radiofrequency group (intervention group, IG) or a deactivated capacitive resistive monopolar radiofrequency group (control group, CG). Both groups will receive pain education and physiotherapeutic techniques (myofascial therapy, trigger point therapy, and/or manual therapy). Participants, the investigators performing the intervention, and the statistical analyses will be blinded.

An analysis of the results will be carried out at 6 and 10 weeks of treatment.

\section{Location}

This trial will take place at RAPbarcelona, a pelvic floor specialized physiotherapy center in Barcelona.

\section{Participants}

Patients receiving their first consultation at the center, or those referred by other health professionals familiar with the protocol of this study, will be invited to participate.

To be eligible, participants must meet the following inclusion criteria are of legal age, have suffered from CPPS for 6 months or more (etiologies will include myofascial syndrome, endometriosis, adenomyosis, inflammatory prostatitis, bladder pain syndrome, levator ani syndrome, pudendal nerve syndrome, or nonspecific CPPS), and agree to participate in the study granting signed informed consent. Exclusion criteria include undergoing other conservative treatments during the study (manual therapy, physical therapy, osteopathy, chiropractic, massage), having undergone treatment with chemotherapy or radiotherapy in the pelvic area, having recently undergone an oncological process, being pregnant, having undergone surgery in the pelvic area in the last 3 months, presenting fibromyalgia or chronic fatigue, suffering serious psyche disorders, presenting hypersensitivity in the skin that may be in contact with the treatment, or suffering from neuromuscular diseases.

\section{Procedure}

Patients who agree to participate in the study will receive CRMRF therapy for 30 min once a week. The first 
session, lasting between 45 and $60 \mathrm{~min}$, will serve to inform the patient, obtain signed informed consent, resolve any doubts about the study or questionnaires, and explain the theory of pain and health education.

At baseline, participants will undergo an initial assessment where data on age, medical history, surgical history, and clinical data will be collected. According to criteria used in previous similar studies [41, 42] palpation of the abdominal, lumbosacral, and perineal region will be performed, followed by internal palpation using the index finger at the vaginal and/or anal level to palpate the pelvic floor muscles, connective tissue, and internal organs, and to localize pain. During the first visit, the visual analog scale (VAS) will be used to measure the intensity of pain, the health questionnaire Short Form 12 (SF-12) to assess the quality of life, the Tampa Scale for Kinesiophobia (TSK-11) to assess kinesiophobia, and the Pain Catastrophizing Scale (PCS) to assess catastrophism. The same tests will be re-evaluated after 6 and 10 sessions. Also, at each session, treatment adherence and possible adverse events of the therapy will be identified and recorded in a database designed for the project.

The most common adverse reaction to the application of CRMRF, particularly at the beginning of treatment, is an increase in pain in the area lasting approximately 2 to 3 days, which can be controlled with the local application of heat and the use of oral analgesics. In rare cases, due to the local application of heat, dermal irritation could appear. In this case, topical treatments may be applied. If the dermal irritation persists in the next session (after 1 week), it will be noted on the patient's record sheet and the intervention will cease until it is completely resolved.

A total of 10 treatment physiotherapy sessions will be held weekly (Table 1).
Both groups will follow the same protocol, which will consist of applying the CRMRF (INDIBA Activ CT8 ${ }^{\circ}$, INDIBA S.A, Sant Quirze del Vallès, Barcelona, Spain) at $2 \%$ to induce an electrical and athermic effect, along with pain education and physiotherapeutic techniques $[43,44]$ administered at the same time as the CRMRF according to the location of the pain (Table 2). Participants will be placed comfortably in a supine or prone position (depending on the area to be treated) with a pillow under their heads, undressed from the waist down. The plate will be placed on the abdomen or lower back depending on the patient's position, and the $32 \mathrm{~mm}$ resistive electrode will be used to apply the CRMRF to the affected area.

Participants in the IG will receive treatment with the activated CRMRF (emitting electrical signal) while participants in the CG will receive the same treatment with the deactivated CRMRF (not emitting electrical signal).

This CRMRF equipment, specifically modified for research purposes, is designed to perform both the conventional treatment (IG) and a placebo treatment (CG) without any visible difference to either the therapist or the participant. The equipment, fully adapted for our research, produces automatic randomization for each participant according to the order of the study assignment.

Pain education will consist of basic theory about gate control [45], concepts of pain and central sensitization, and a basic explanation of the neurotransmitters that influence the increase or decrease in pain [46-48].

The physiotherapeutic techniques that will be performed in each session will be the same in all individualized treatment sessions for each patient and assigned according to the location of the pain (Table 2). These techniques will be those recommended by the literature for the treatment of CPPS and will consist of myofascial

Table 1 Treatment sessions

\begin{tabular}{|c|c|c|}
\hline & Intervention group (IG) & Control group (CG) \\
\hline \multirow[t]{2}{*}{ Session 1} & \multicolumn{2}{|c|}{$\begin{array}{l}\text { Review of the information sheet and signing of informed consent. } \\
\text { Collection and recording of baseline data (age, sociodemographic data, clinical data, and medical and surgical history). Self-completion } \\
\text { of tests (VAS, SF-12, TSK-11, and PCS). }\end{array}$} \\
\hline & $\begin{array}{l}\text { Application of physiotherapeutic techniques with activated CRMRF. } \\
\text { Explanation of the theory of pain and health education. }\end{array}$ & $\begin{array}{l}\text { Application of physiotherapeutic techniques with deactivated } \\
\text { CRMRF. } \\
\text { Explanation of the theory of pain and health education. }\end{array}$ \\
\hline $\begin{array}{l}\text { Session 2- } \\
5\end{array}$ & $\begin{array}{l}\text { Session protocol: } \\
\text { - Registration of possible discomfort or adverse events perceived } \\
\text { by the patient. } \\
\text { - Application of physiotherapeutic techniques with activated CRMR } \\
\text { F. } \\
\text { - Pain education clarifications }\end{array}$ & $\begin{array}{l}\text { Session protocol: } \\
\text { - Registration of possible discomfort or adverse events perceived } \\
\text { by the patient. } \\
\text { - Application of physiotherapeutic techniques with deactivated } \\
\text { CRMRF. } \\
\text { - Pain education clarifications }\end{array}$ \\
\hline Session 6 & \multicolumn{2}{|l|}{$\begin{array}{l}\text { Collection of VAS, SF-12, TSK-11, and PCS tests. } \\
\text { Session protocol (as described in session 2-5) }\end{array}$} \\
\hline $\begin{array}{l}\text { Session 7- } \\
9\end{array}$ & \multicolumn{2}{|l|}{ Session protocol (as described in session 2-5) } \\
\hline Session 10 & \multicolumn{2}{|c|}{$\begin{array}{l}\text { Session protocol (as described in session 2-5) } \\
\text { Assessment of VAS, SF-12, TSK-11, PCS tests, evolution of the pathology, and referral (if required). }\end{array}$} \\
\hline
\end{tabular}


Table 2 Physiotherapeutic techniques and position of the patient during treatment sessions, depending on the location of the pain

\begin{tabular}{lll}
\hline & (abdomen, pubis, groin, perineum, vagina, penis, testicles) & $\begin{array}{l}\text { Posterior location } \\
\text { (lumbar, sacrum, coccyx, buttocks, anus, rectum) }\end{array}$ \\
\hline Position: & Patient in supine position. CRMRF plate on lower back & Patient in the prone position. CRMRF plate on abdomen \\
Techniques: & - Abdominal area: & - Lumbosacral area: \\
& - Lift techniques of the peritoneum & - Relaxation of the quadratus lumbar \\
& - Liberation of the urachus & - Relaxation of the paravertebral muscles \\
- Groin area: & - Gluteal area: \\
- Stretching the inguinal ligament & - Decompression of the pudendal nerve in the greater sciatic foramen \\
- Myotensive techniques of the internal obturator & - Stretching of the sacrociatic ligament \\
- Vulvar, perineal and vaginal area: & - Stretching of the sacrotuberous ligament \\
- Relaxation of the superficial fascia of the perineum & - Release of the pudendal nerve in the ischiorectal fossa \\
- Stretching the prevesical ligament & - Myotensive techniques of the pyramidal \\
- Uterine release techniques & - Myotensive techniques of the external obturator \\
- Stretching of the round ligament & - Anorectal area: \\
- Stretching of the wide ligament & - Sacral plexus release techniques \\
- Relaxation of the sacrorectogenitopubian laminae & - Relaxation of the sacrorectogenitopubian laminae \\
- Release of the pudendal nerve in Alcock's canal & - Stretching the Denonvilliers fascia \\
- Penis and testicular area: & - Prostate release techniques \\
- Relaxation of the superficial fascia of the perineum & \\
- Relaxation of the deep fascia of the perineum & \\
- Testicular drainage & \\
If there is scarring, manual scar work is performed, and the $35 \mathrm{~mm}$ resistive electrode is applied over it.
\end{tabular}

induction techniques, trigger point therapy, and manual therapy with the aim of improving the elasticity of the musculature and fascial tissue and improving blood flow. They will be performed with smooth, slow, and increasingly direct movements, beginning distally and becoming more localized [49]. This information will be emphasized to the patient to improve treatment and follow-up, as well as the fact that this ordinarily costly treatment will have no cost for study participants.

As this is a study with multiple tests and interventions, several physical therapists will be needed to carry it out. For this reason, and to avoid errors due to lack of standardization, there will be training in the application of the therapy and data collection for all physiotherapists who participate in the study.

\section{Outcome measures}

Participants will complete three study assessments: a baseline assessment and at 6 and 10 weeks after the first session.

Primary outcome:

- The intensity of pain: According to the VAS score, which will be evaluated in the first, sixth, and tenth sessions of the study. This quantitative and subjective variable consists of marking the degree of pain intensity in a straight horizontal line of a fixed length of $10 \mathrm{~cm}$. The ends are defined as the extreme limits of the parameter to be measured from left (worst) to right (best) [50, 51].

Secondary outcomes:

- The quality of life related to health: Measured with the SF-12 Quality of Life health questionnaire.
Specifically, the Spanish adaptation of the SF-12 Health Survey [52, 53] done by Alonso et al. [54, 55] will be used. The SF-12 is a reduced version of the SF-36 Health Questionnaire designed for cases in which a shorter questionnaire is required. While the SF-12 can be answered in an average of $\leq 2 \mathrm{~min}$, the SF-36 takes between 5 and 10 min to complete. It consists of 12 items from the 8 dimensions of the SF-36 (physical function, social function, physical role, emotional role, mental health, vitality, body pain, and general health status). A higher score means better quality of life.

- The kinesiophobia: Fear of movement will be measured by the Tampa Scale for Kinesiophobia (TSK-11). This questionnaire, created by Miller et al. [56], quantifies the intensity of kinesiophobia suffered by the patient. The reduced version and adaptation to Spanish by Gómez-Pérez et al. [57] will be used. It consists of 11 statements that the patient must answer using a Likert-type scale from 1 (totally disagree) to 4 (totally agree). A higher score means a greater degree of kinesiophobia.

- The catastrophizing: Measured with the Pain Catastrophizing Scale (PCS) [58]. This 13-item questionnaire assesses the patient's catastrophic thoughts using a five-point Likert scale. It consists of three subscales (rumination, magnification, and hopelessness). A higher score means a greater degree of catastrophizing. The Spanish adaptation validated by García Campayo et al. [59] will be used.

- Sociodemographic variables, pathological history, and clinical history: Assessed in the first treatment session and collected through a standardized clinical history. 
- Adverse events: Recorded in each of the treatment sessions through patient references to his or her status and evolution.

- Adherence to treatment: Assessed in each of the treatment sessions and collected through a compliance form designed for the project.

\section{Schedule Table 3}

\section{Sample size}

To estimate the sample size, version 7.12 (April 2012) of the sample size calculator of the "GRANMO" program was used. This version can be obtained at the following link: https://www.imim.es/ofertadeserveis/softwarepublic/granmo/.

For this estimate, alpha values of $5 \%$ and beta values of $20 \%$ (power of $80 \%$ ) were taken into account. Based on data published in the literature [60] and applying a common standard deviation of 3 and a difference equal to or greater than 2 in the VAS, 40 patients are needed for each leg of the study, assuming a maximum percentage of follow-up losses/dropouts of $10 \%$.

\section{Selection of the sample}

The selection of the sample will be done by sampling consecutive cases from the RAPbarcelona clinic in Barcelona. Health professionals from other institutions will be contacted to increase referrals to the center and an advertising campaign will be carried out on social networks. In physiotherapist appointments, patients with CPPS will be referred to the principal investigator. The protocol will be clearly explained to each of the interested patients who meet the selection criteria, and patients will be asked to sign an informed consent if they choose to participate. Patients will then be allocated to one of the two study groups.

\section{Random allocation of groups}

Once participants are included in the study, they will be identified by the number from their computerized medical record and will be ordered sequentially and consecutively from 1 to 80 according to the order of recruitment. To assign interventions, CRMRF team engineers will enter the randomized sequence corresponding to each number from 1 to 80 into the study software to designate the CG and IG participants. In order to keep the assigned study group hidden from the patient, the physiotherapist, and the main researcher, the following four indications will be taken into account: (1) No parameter will appear on the screen visible to the CRMRF team that indicates whether the equipment emits an electrical signal. (2) The current intensity parameter will be $2 \%$ for all participants to prevent the intervention group patients from perceiving any thermal effect. (3) The physiotherapists will apply the CRMRF by manipulating the equipment with the handle and never with the electrode to avoid any sensation. They will be trained before starting the study. (4) The sequence of randomization and allocation will be kept hidden at all times from all patients, professionals, and the main researcher until the statistical analysis once the intervention is completed.

Table 3 The different schedule phases are shown in italics

\begin{tabular}{|c|c|c|c|c|c|c|}
\hline & Recruitment & Session 1 & Sessions 2-5 & Session 6 & Sessions 7-9 & Session 10 \\
\hline \multicolumn{7}{|l|}{ Recruitment: } \\
\hline Selection screening & $x$ & & & & & \\
\hline Informed consent & $x$ & & & & & \\
\hline Allocation & $x$ & & & & & \\
\hline \multicolumn{7}{|l|}{ Interventions: } \\
\hline Intervention CG (deactivated CRMRF & & $x$ & $x$ & $x$ & $x$ & $x$ \\
\hline Intervention IG (activated CRMRF) & & $x$ & $x$ & $x$ & $x$ & $x$ \\
\hline \multicolumn{7}{|l|}{ Evaluations: } \\
\hline Demographic variables & & $x$ & & & & \\
\hline Clinical variables & & $x$ & & & & \\
\hline VAS & & $x$ & & $x$ & & $x$ \\
\hline SF-12 & & $x$ & & $x$ & & $x$ \\
\hline TSK-11 & & $x$ & & $x$ & & $x$ \\
\hline PCS & & $x$ & & $x$ & & $x$ \\
\hline Compliance form & & $x$ & $x$ & $x$ & $x$ & $x$ \\
\hline Recording of adverse events & & $x$ & $x$ & $x$ & $x$ & $x$ \\
\hline
\end{tabular}




\section{Collection, management, and data analysis}

Data will be collected in a specific database coded for this study, which will only be available to the main researcher. The database and statistical analysis will be performed with IBM SPSS Statistics 24.0 software.

First, a descriptive analysis of the characteristics of the patients included in both study groups, as well as the outcome variables will be carried out. To do this, absolute and relative frequencies (percentages) will be estimated for qualitative variables, and mean or median and standard deviation or range, respectively, depending on the normality of the distribution, for quantitative variables. Then, the comparative analysis of the two treatment groups will be carried out using the Chi-square test for qualitative variables and the Student's $t$ test for quantitative variables. Additionally, different associations between diverse variables will be analyzed. To check for the efficacy of the study treatments, intention to treat (ITT) and by protocol (PP) analysis will be performed.

The comparison of results will be done by promptly estimating the differences of the mean values of the outcome variables with their corresponding 95\% confidence intervals (95\% CI) and standard deviation (SD). Additionally, the adjusted differences will be calculated following the indications of the CONSORT document [61].

All data will be systematically included in the statistical database and an analysis of the results will be carried out individually for each participant both in the middle of the treatment (fifth session) and at the end (tenth session) to evaluate the evolution. The trial will cease if significant worsening, absolute improvement (VAS $=0$ ), or unknown serious adverse events occur. A full preliminary results analysis will be performed when one-third of the sample size has been reached and the final analysis will be performed once the last participant has completed the intervention.

In all cases, the level of statistical significance established will be the usual (5\%); therefore, statistically significant differences will be considered when $\mathrm{p}$ values are less than 0.05 .

\section{Discussion}

The results of this study will make it possible to prove that CRMRF benefits the treatment of patients with CPPS together with physiotherapeutic techniques and pain education. These results could offer an alternative conservative treatment option for these patients.

\section{Trial status}

This is the first version of the protocol (January 28, 2021). Recruitment began in April 2019 and the intervention was put on hold due to the coronavirus crisis. For this reason, completion is expected by next April.

\section{Abbreviations}

CG: Control group; CPPS: Chronic pelvic pain syndrome; CRMRF: Capacitive resistive monopolar radiofrequency; IG: Intervention group; PCS: Pain Catastrophizing Scale; SF-12: Health Questionnaire Short Form 12; TSK11: Tampa Scale for Kinesiophobia; VAS: Visual analog scale

\section{Supplementary Information}

The online version contains supplementary material available at https://doi. org/10.1186/s13063-021-05321-6.

\section{Additional file 1.}

\section{Acknowledgements}

We want to thank Mr. Sebastià Sendrós and his staff (INDIBA SAU, ES) who have volunteered their technical support in helping us with the randomization of the equipment (INDIBA Activ CT8 ${ }^{\oplus}$ ) to be used for this study. Thank you to Dr. Emilia Sánchez and Ms. Helen Poliquin for their support in reviewing this article.

\section{Authors' contributions}

ACM and IRG were responsible for the study concept and design. MAMP collaboratively conceptualized the study objectives and methodology and provided a critical revision of the manuscript. RPA, SK, and LBR helped conceptualize and design the study. All authors read and approved the final manuscript. The authors declare that INDIBA SAU (ES) has no role in study design, data collection and analysis, decision to publish, or preparation of the manuscript.

\section{Funding}

No funding.

Availability of data and materials Not applicable.

\section{Declarations}

\section{Ethics approval and consent to participate}

This protocol has been evaluated and approved by the Research Ethics Committee of the Vall d'Hebron University Hospital (Comité de Ética de Investigación con Medicamentos y comisión de proyectos de investigación del Hospital Universitari Vall d'Hebron) (PR(RAP)361/2018).

The development of the project is based on following and respecting the bioethical principles of beneficence, nonmaleficence, autonomy, justice, dignity, and privacy, the Declaration of Human Rights, the Belmont Report, and the International Declaration on Bioethics and Human Rights of UNESCO. It is also grounded in the statements of the World Medical Association of Helsinki, the Deontological Code of the Association of Medical Colleges of Spain, and the Deontological Code of Physiotherapists of Catalonia and Spain.

All patients will be informed verbally and via an information sheet and will be required to sign the informed consent. Participation in the study may be interrupted by the patient at any time if desired, and without negative consequences for the individual.

All data collected will be confidential, respecting the Spanish data protection law (LOPD Ley Orgánica 3/2018, de 5 de diciembre, de Protección de Datos Personales y garantía de los derechos digitales). Likewise, the privacy of each participant will be respected at all times. Only the principal investigator, the physiotherapists who perform the interventions, and the statistical analyst will have access to the final data set.

This clinical trial will be registered at ClinicalTrials.gov and data will be updated systematically, as well as any changes to the protocol. The aim is to publish the results in the form of a doctoral thesis by the principal investigator.

Consent for publication

Not applicable.

Competing interests

The authors declare that they have no competing interests. 


\section{Author details}

Rehabilitación Abdomino-Pelviana (RAPbarcelona SL), Barcelona, Spain. ${ }^{2}$ Servicio de Ginecología, Instituto Clínic de Ginecología, Obstetricia y Neonatología, Hospital Clínic de Barcelona, Barcelona, Spain. ${ }^{3}$ Institut Universitari d'Investigació en Atenció Primària Jordi Gol (IDIAP-Jordi Gol), Barcelona, Spain. ${ }^{4}$ Institut Català de la Salut (ICS), Barcelona, Spain. 5 Departament de Pediatria, Obstetricia i Ginecologia i Medicina Preventiva, Universitat Autònoma de Barcelona (UAB), Bellaterra, Spain. ${ }^{6}$ Fundació Universitària del Bages (FUB), Barcelona, Spain. ' Servicio de Fisioterapia, Womens Salud y Bienestar de la Mujer SL, Barcelona, Spain. ${ }^{8}$ Servicio de Fisioterapia, Instituto Médico Tecnológico SL, Barcelona, Spain. 'Blanquerna School of Health Science-Universitat Ramon Llull, Barcelona, Spain.

${ }^{10}$ Universidad Internacional de Catalunya (UIC), Barcelona, Spain.

\section{Received: 31 January 2021 Accepted: 8 May 2021}

\section{Published online: 20 May 2021}

\section{References}

1. Uroweb. Chronic pelvic pain. 2017. https://uroweb.org/guideline/chronicpelvic-pain/. Assessed 14 May 2021

2. Valdivia Jiménez Ml. Abordaje del dolor en una unidad de suelo pélvico. Necesidad de equipos multidisciplinares. Suelo Pélvico. 2013;9(1):29-35.

3. Ahangari A. Prevalence of chronic pelvic pain among women: an updated review. Pain Phys. 2014;17(2):e141-7.

4. Grinberg K, Granot M, Lowenstein L, Abramov L, Weissman-Fogel I. A common pronociceptive pain modulation profile typifying subgroups of chronic pelvic pain syndromes is interrelated with enhanced clinical pain. Pain. 2017;158(6):1021-9. https://doi.org/10.1097/j.pain.0000000000000869.

5. Steege JF, Siedhoff MT. Chronic pelvic pain. Obstet Gynecol. 2014 Sep; 124(3):616-29. https://doi.org/10.1097/AOG.0000000000000417.

6. Cheong YC, Smotra G, Williams ACDC. Non-surgical interventions for the management of chronic pelvic pain. Cochrane Database Syst Rev. 2014;(3) CD008797. https://doi.org/10.1002/14651858.CD008797.pub2. Accessed 16 May 2021

7. Twiddy H, Bradshaw A, Chawla R, Johnson S, Lane N. Female chronic pelvic pain: the journey to diagnosis and beyond. Pain Manag. 2017;7(3):155-9. https://doi.org/10.2217/pmt-2016-0052.

8. Krieger JN, Lee SW, Jeon J, Cheah PY, Liong ML, Riley DE. Epidemiology of prostatitis. Int J Antimicrob Agents. 2008;31(Suppl 1):S85-90.

9. Bryant C, Cockburn R, Plante A-F, Chia A. The psychological profile of women presenting to a multidisciplinary clinic for chronic pelvic pain: high levels of psychological dysfunction and implications for practice. J Pain Res. 2016;9:1049-56. https://doi.org/10.2147/JPR.S115065

10. Miller-Matero LR, Saulino C, Clark S, Bugenski M, Eshelman A, Eisenstein D. When treating the pain is not enough: a multidisciplinary approach for chronic pelvic pain. Arch Womens Ment Health. 2016;19(2):349-54. https:// doi.org/10.1007/s00737-015-0537-9.

11. Romão APMS, Gorayeb R, Romão GS, Poli-Neto OB, dos Reis FJC, Rosa-eSilva JC, et al. High levels of anxiety and depression have a negative effect on quality of life of women with chronic pelvic pain. Int J Clin Pract. 2009; 63(5):707-11. https://doi.org/10.1111/j.1742-1241.2009.02034.x

12. Lorençatto C, Petta CA, Navarro MJ, Bahamondes L, Matos A. Depression in women with endometriosis with and without chronic pelvic pain. Acta Obstet Gynecol Scand. 2006:85(1):88-92. https://doi.org/10.1080/0001634 0500456118

13. Williams DA. The importance of psychological assessment in chronic pain. Curr Opin Urol. 2013;23(6):554-9. https://doi.org/10.1097/MOU.0b013e3283 652 af1.

14. Till SR, As-Sanie S, Schrepf A. Psychology of chronic pelvic pain: prevalence, neurobiological vulnerabilities, and treatment. Clin Obstet Gynecol. 2019; 62(1):22-36. https://doi.org/10.1097/GRF.0000000000000412.

15. Yosef $A$, Allaire $C$, Williams $C$, et al. Multifactorial contributors to the severity of chronic pelvic pain in women. Am J Obstet Gynecol. 2016;215(6):760 e1e760.e14.

16. McPeak AE, Allaire C, Williams C, Albert A, Lisonkova S, Yong PJ. Pain catastrophizing and pain health-related quality-of-life in endometriosis. Clin J Pain. 2018;34(4):349-56. https://doi.org/10.1097/AJP.0000000000000539.

17. Sewell M, Churilov L, Mooney S, Ma T, Maher P, Grover SR. Chronic pelvic pain - pain catastrophizing, pelvic pain and quality of life. Scand J Pain. 2018;18(3):441-8. https://doi.org/10.1515/sjpain-2017-0181.
18. Granot M. Personality traits associated with perception of noxious stimuli in women with vulvar vestibulitis syndrome. J Pain. 2005;6(3):168-73. https:// doi.org/10.1016/j.jpain.2004.11.010.

19. Lowenstein L, FitzGerald MP, Kenton K, Hatchett L, Durazo-Arvizu R, Mueller ER, et al. Evaluation of urgency in women, with a validated Urgency, Severity and Impact Questionnaire (USIQ). Int Urogynecol J Pelvic Floor Dysfunct. 2009;20(3):301-7. https://doi.org/10.1007/s00192-008-0770-0.

20. Lowenstein L, Vardi Y, Deutsch M, Friedman M, Gruenwald I, Granot M, et al. Vulvar vestibulitis severity-assessment by sensory and pain testing modalities. Pain. 2004; 107(1-2):47-53. https:/doi.org/10.1016/j.pain.2003.09.012

21. van Lankveld JJ, Granot M, Weijmar Schultz WC, Binik YM, Wesselmann U, Pukall CF, et al. Women's sexual pain disorders. J Sex Med. 2010;7(1 Pt 2): 615-31. https://doi.org/10.1111/j.1743-6109.2009.01631.x.

22. Allaire C, Williams C, Bodmer-Roy S, et al. Chronic pelvic pain in an interdisciplinary setting: 1-year prospective cohort. Am J Obstet Gynecol. 2018;218(1):114.e1-e114.e12.

23. Thomtén J, Karlsson A. Psychological factors in genital pain: the role of fearavoidance, pain catastrophizing and anxiety sensitivity among women living in Sweden. Scand J Pain. 2014;5(3):193-9. https://doi.org/10.1016/j.sjpa in.2014.01.003

24. Grinberg K, Weissman-Fogel I, Lowenstein L, Abramov L, Granot M. How does myofascial physical therapy attenuate pain in chronic pelvic pain syndrome? Pain Res Manag. 2019;2019:6091257.

25. Klotz S, Ketels G, Löwe B, Brünahl C. Myofascial findings and phychopathological factors in patients with chronic pelvic pain syndrome. Pain Med. 2018;0:1-11.

26. Grinberg K, Sela Y, Nissanholtz-Gannot R. New insights about Chronic Pelvic Pain Syndrome (CPPS). Int J Environ Res Public Health. 2020;17(9):3005. https://doi.org/10.3390/ijerph17093005

27. Klotz S, Schön M, Ketels G, Löwe B, Brünahl C. Physiotherapy management of patients with chronic pelvic pain (CPP): a systematic review. Physiother Theory Pract. 2019:35(6):516-32. https://doi.org/10.1080/09593985.2018.1455251.

28. Osti R, Pari C, Salvatori G, Massari L. Tri-length laser therapy associated to tecar therapy in the treatment of lowback pain in adults: a preliminary report of a prospective case series. Lasers Med Sci. 2015;30(1):407-12. https://doi.org/10.1007/s10103-014-1684-3.

29. Kumaran B, Watson T. Thermal build-up, decay and retention responses to local therapeutic application of $448 \mathrm{kHz}$ capacitive resistive monopolar radiofrequency: a prospective randomised crossover study in healthy adults. Int J Hyperth. 2015;31(8):883-95. https://doi.org/10.3109/02656736.2015.1092172.

30. Úbeda A, Hernández-Bule ML, Trillo MA, Cid MA, Leal J. Cellular response to non-thermal doses of radiofrequency currents used in electro-thermal therapy. J Jpn Soc Laser Surg Med. 2006;27(3):187.

31. Yokota $Y$, Tashiro $Y$, Suzuki $Y$, Tasaka S, Matsushita T, et al. Effect of capacitive and resistive electric transfer on tissue temperature, muscle flexibility, and blood circulation. J Nov Physiother. 2017;7:325.

32. Watson T. Electrotherapy: evidence-based practice. 12th ed. London: Elsevier Churchill Livingstone; 2008

33. Lehmann J, DeLateur B. Therapeutic heat. In: Lehmann J, editor. Therapeutic heat and cold. 4th ed. Baltimore: Williams \& Wilkins; 1990. p. 470-4.

34. Prentice W, Draper D. Shortwave and microwave diathermy. In: Prentice W, editor. Therapeutic modalities in rehabilitation. 4th ed. New York: McGrawHill; 2011. p. 433-62.

35. Kumaran B, Watson T. Radiofrequency-based treatment in therapyrelated clinical practice - a narrative review. Part I: acute conditions. Phys Ther Rev. 2015;20(4):241-54. https://doi.org/10.1179/1743288X15Y.0000000016.

36. Fuentes-Márquez P, Cabrera-Martos I, Valenza MC. Physiotherapy interventions for patients with chronic pelvic pain: a systematic review of the literature. Physiother Theory Pract. 2019;35(12):1131-8. https://doi.org/1 $0.1080 / 09593985.2018 .1472687$

37. Notarnicola A, Maccagnano G, Gallone MF, Covelli I, Tafuri S, Moretti B. Short term efficacy of capacitive-resistive diathermy therapy in patients with low back pain: a prospective randomized controlled trial. J Biol Regul Homeost Agents. 2017;31(2):509-15.

38. Wiegerinck Jl, Kerkhoffs GM, van Sterkenburg MN, Sierevelt IN, van Dijk CN. Treatment for insertional Achilles tendinopathy: a systematic review. Knee Surg Sports Traumatol Arthrosc. 2013;21(6):1345-55. https://doi.org/10.1007/ s00167-012-2219-8.

39. Costantino C, Vulpiani MC, Romiti D, Vetrano M, Saraceni VM. Cryoultrasound therapy in the treatment of chronic plantar fasciitis with heel spurs. A randomized controlled clinical study. Eur J Phys Rehabil Med. 2014;50(1):39-47. 
40. Lideo L, Milan R. Ultrasound monitoring of shortwave diathermic treatment of gastrocnemius strain in a dog. J Ultrasound. 2013;16(4):231-4. https://doi. org/10.1007/s40477-013-0044-7.

41. Bonder JH, Chi M, Rispoli L. Myofascial pelvic pain and related disorders. Phys Med Rehabil Clin N Am. 2017;28(3):501-15. https://doi.org/10.1016/j. pmr.2017.03.005.

42. Simons DG, Travell JG. Dolor y disfunción miofascial: El manual de los puntos gatillo (vol.2): extremidades inferiores: Ed. Panamericana; 2010.

43. Charles D, Hudgins T, MacNaughton J, Newman E, Tan J, Wigger M. A systematic review of manual therapy techniques, dry cupping and dry needling in the reduction of myofascial pain and myofascial trigger points. J Bodyw Mov Ther. 2019;23(3):539-46. https://doi.org/10.1016/j.jbmt.2019.04.001.

44. Montenegro ML, Braz CA, Rosa-e-Silva JC, Candido-dos-Reis FJ, Nogueira AA, Poli-Neto OB. Anaesthetic injection versus ischemic compression for the pain relief of abdominal wall trigger points in women with chronic pelvic pain. BMC Anesthesiol. 2015;15(1):175. https://doi.org/10.1186/s12871-015-0155-0.

45. Melzack R, Wall P. Pain mechanisms: a new theory. Science. 1965;150(3699): 971-9. https://doi.org/10.1126/science.150.3699.971.

46. Aredo JV, Heyrana KJ, Karp BI, Shah JP, Stratton P. Relating chronic pelvic pain and endometriosis to signs of sensitization and myofascial pain and dysfunction. Semin Reprod Med. 2017:35(1):88-97. https:/doi.org/10.1055/s-0036-1597123.

47. Kaya S, Hermans L, Willems T, Roussel N, Meeus M. Central sensitization in urogynecological chronic pelvic pain: a systematic literature review. Pain Phys. 2013;16(4):291-308.

48. Nijs J, Meeus M, Versijpt J, Moens M, Bos I, Knaepen K, et al. Brain-derived neurotrophic factor as a driving force behind neuroplasticity in neuropathic and central sensitization pain: a new therapeutic target? Expert Opin Ther Targets. 2015;19(4):565-76. https://doi.org/10.1517/14728222.2014.994506.

49. Laimi K, Mäkila A, Bärlund E, Katajapuu N, Oksanen A, Seikkula V, et al. Effectiveness of myofascial release in treatment of chronic musculoskeletal pain: a systematic review. Clin Rehabil. 2018;32(4):440-50. https://doi.org/1 $0.1177 / 0269215517732820$

50. Gould D, Kelly D, Goldstone L, Gammon J. Visual analogue scale (VAS). J Clin Nurs. 2001;10(5):697-706. https://doi.org/10.1046/j.1365-2702.2001.00525.x.

51. Streiner DL, Norman GR. Health measurement scales: a practical guide to their development and use. New York: Oxford University Press; 1989.

52. Ware JE Jr, Kosinski M, Keller SD. A 12-item short-form health survey: construction of scales and preliminary tests of reliability and validity. Med Care. 1996;34(3):220-33. https://doi.org/10.1097/00005650-199603000-00003.

53. Gandek B, Ware JE, Aaronson NK, Apolone G, Bjorner JB, Brazier JE, et al. Crossvalidation of item selection and scoring for the SF-12 Health Survey in nine countries: results from the IQOLA Project. International Quality of Life Assessment. J Clin Epidemiol. 1998;51(11):1171-8. https:/doi.org/10.1016/S0895-4356(98)00109-7.

54. Vilagut G, Ferrer M, Rajmil M, Rebollo P, Permanyer-Miralda G, Quintana JM, et al. E cuestionario de salud SF-36 espa.ol: una d.cada de experiencia y nuevos desarrollos. Gac Sanit. 2005;19(2):135-50. https:/doi.org/10.1157/13074369.

55. Alonso J, Regidor E, Barrio G, Prieto L, Rodriguez C, de la Fuente L. Valores poblacionales de referencia de la versi.n espa.ola del Cuestionario de Salud SF- 36. Med Clin. 1998:111:410-6.

56. Miller R, Kori S, Todd D. The Tampa Scale: a measure of kinesiophobia. Clin J Pain. 1991;7(1):51. https://doi.org/10.1097/00002508-199103000-00053.

57. Gómez-Pérez L, López-Martínez AE, Ruiz-Párraga GT. Psychometric properties of the Spanish version of the Tampa Scale for Kinesiophobia (TSK). J Pain. 2011;12(4):425-35. https://doi.org/10.1016/j.jpain.2010.08.004.

58. Sullivan M, Bishop S, Pivik J. The pain catastrophizing scale: development and validation. Physchol Assess. 1995;7(4):524-32. https://doi.org/10.1037/1 040-3590.7.4.524.

59. García Campayo J, Rodero B, Alda M, Sobradiel N, Montero J, Moreno S. Validation of the spanish version of the pain catastrophizing scale in fibromyalgia. Med Clin. 2008;131(13):487-93. https://doi.org/10.1157/13127277.

60. Parker SL, Adogwa O, Paul AR, Anderson WN, Aaronson O, Cheng JS, et al. Utility of minimum clinically important difference in assessing pain, disability, and health state after transforaminal lumbar interbody fusion for degenerative lumbar spondylolisthesis. J Neurosurg Spine. 2011;14(5):598604. https://doi.org/10.3171/2010.12.SPINE10472.
61. Moher D, Hopewell S, Schulz KF, Montori V, Gøtzsche PC, Devereaux PJ, et al. CONSORT 2010 explanation and elaboration: updated guidelines for reporting parallel group randomised trials. BMJ. 2010;340:c869.

\section{Publisher's Note}

Springer Nature remains neutral with regard to jurisdictional claims in published maps and institutional affiliations.
Ready to submit your research? Choose BMC and benefit from:

- fast, convenient online submission

- thorough peer review by experienced researchers in your field

- rapid publication on acceptance

- support for research data, including large and complex data types

- gold Open Access which fosters wider collaboration and increased citations

- maximum visibility for your research: over $100 \mathrm{M}$ website views per year

At BMC, research is always in progress.

Learn more biomedcentral.com/submissions 